\title{
Sachgerecht ist, wenn man der Sache GERECHT wird!
}

\section{Urs Stoffel}

Dr. med., Mitglied des FMH-Zentralvorstandes, Departementsverantwortlicher Ambulante Versorgung und Tarife

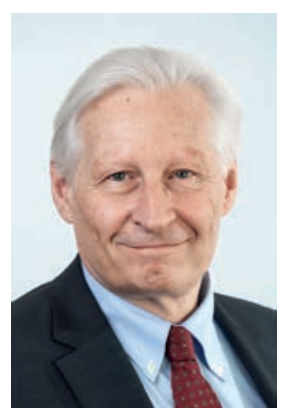

Am 21. Juni 2017 endete die Vernehmlassung zum geplanten Tarifeingriff des Bundesrates in die Struktur des Ärztetarifs TARMED. Eine wahre Flut von empörten und entrüsteten Stellungnahmen aus der Ärzteschaft erreichten das BAG. Aber nicht nur Akteure innerhalb der Ärztekreise, sondern auch weitere Verbände äusserten sich in ihren Vernehmlassungsantworten kritisch und besorgt zu den Massnahmen des Bundesrates. Die Kritik und der Unmut der Ärzteschaft zum Tarifeingriff wurden auch breit in den Medien thematisiert. Dabei war von dieser Seite und von der Politik immer wieder zu hören, dass die Ärzte selber schuld seien, weil sie es in den letzten Jahren nicht geschafft haben, zusammen mit den Tarifpartnern eine revidierte Tarifstruktur beim Bundesrat zur Genehmigung einzureichen. Die Ungeduld und das Unverständnis in diesen Aussagen sind unverkennbar und teilweise auch nachvollziehbar.

\section{Ein Gerichtsurteil mit weitreichenden Folgen!}

Grosse Aufmerksamkeit erhielt mitten in der Vernehmlassungsphase am 29. Mai 2017 die Veröffentlichung des Urteils des Schiedsgerichts des Kantons Luzern: Das Urteil befasst sich mit der Rechtmässigkeit des ersten bundesrätlichen Tarifeingriffs vom 20. Juni 2014. Das (noch nicht rechtskräftige) Urteil kommt zum Schluss, dass durch diesen Tarifeingriff das Gebot der Sachgerechtigkeit und der betriebswirtschaftlichen Bemessung nach Art. 43 Abs. 4 KVG verletzt wurde und dieser Eingriff damit gesetzeswidrig sei.

TARCO: Nur eine Gesamtrevision führt zu einer betriebswirtschaftlichen und sachgerechten ambulanten Tarifstruktur.

Das Gericht hält in seiner Urteilsbegründung fest, dass der Bundesrat gemäss Art. 43 Abs. 5bis KVG das subsidiäre Recht für einen Eingriff in die Tarifstruktur hat, wenn der Tarif nicht mehr sachgerecht ist und sich die Tarifpartner nicht auf eine Revision einigen können. Gleichzeitig unterstreicht das gerichtliche Urteil, dass ein solcher Tarifeingriff die Sachgerechtigkeit des Tarifs wiederherstellen muss. Der Tarifeingriff unterliegt damit den gesetzlichen Bestimmungen von Art. 43 Abs. 4 KVG, der eine betriebswirtschaftliche Bemessung und Sachgerechtigkeit fordert. Noch nie hat sich ein Gericht dazu geäussert, wie ein Tarifeingriff auszusehen hat und an welchen gesetzlichen Bestimmungen er sich zu orientieren hat.

War der Eingriff 2014 noch vergleichsweise einfach und begrenzt, so ist der jetzige Eingriff derart komplex, dass er teilweise zu enormen Verzerrungen und Unwuchten führt. Es fehlen Daten und Fakten, welche die einzelnen vorgeschlagenen Massnahmen begründen. Vor diesem Hintergrund darf man mit gutem Grund behaupten, dass dieser zweite bundesrätliche Tarifeingriff die gesetzlichen Vorgaben der Sachgerechtigkeit und betriebswirtschaftlichen Bemessung erst recht nicht erfüllt.

\section{Projekt TARCO weiterhin zielgerichtet unterwegs!}

Die FMH hat sich immer klar geäussert, dass punktuelle Eingriffe in die veraltete und nicht mehr sachgerechte Tarifstruktur TARMED die Tarifstruktur weiter verzerren und sie damit noch weniger sachgerecht ist. Aus Sicht der FMH ist und bleibt der einzige richtige Weg eine umfassende, sachgerechte und betriebswirtschaftliche Revision des TARMED-Tarifs gemeinsam mit den Tarifpartnern.

Das Projekt TARCO ist weiterhin auf Kurs: Alle $30 \mathrm{Ar}-$ beitsgruppen sind in den verschiedenen Tarifkapiteln an der Arbeit. Einzelne Kapitel sind auch schon in der FMH-internen Vernehmlassung. Das von der Delegiertenversammlung der FMH eingesetzte oberste Entscheidorgan «TARCO COCKPIT», bestehend aus verschiedenen Vertretern der Dachgesellschaften, hat bereits über 40 Entscheide gefällt und tagt regelmässig. In einer nächsten Phase gehen wir nun sukzessive auf die Tarifpartner zu für die weiteren gemeinsamen Verhandlungen.

Unser Ziel bleibt es, durch eine umfassende Gesamtrevision des TARMED mit unseren Tarifpartnern, der Sache GERECHT zu werden. 